\title{
Improving Hong Kong's Elderly Health Care Voucher Scheme: an overview and update
}

\author{
KC Chong *, PhD, H Fung, MB, BS, MHP (NSW), EK Yeoh, MB, BS, FRCP (Edin)
}

School of Public Health and Primary Care, The Chinese University of Hong Kong, Shatin, Hong Kong

Hong Kong Med J 2019;25:494-6

*Corresponding author: marc@cuhk.edu.hk

https://doi.org/10.12809/hkmj187633

\section{Background}

Hong Kong's Elderly Health Care Voucher (EHCV) Scheme was launched as a 3-year pilot scheme in 2009 to develop a long-term strategy to enhance primary care services for the elderly people. The elderly people were expected to choose private healthcare services, which would relieve some of the burden on public healthcare services such as general out-patient clinics and specialist out-patient clinics. At the start of the scheme, HK\$250 in vouchers was given annually to each Hong Kong resident aged $\geq 70$ years. After reviewing the scheme, the annual amounts were increased to HK\$500 and HK\$1000 in 2012 and 2013, respectively. In 2014, the amount was raised to HK\$2000 and its cumulative could be carried forward up to HK\$4000 for subsequent years. ${ }^{1}$ The scheme also allowed the elderly people to claim optometric treatment costs and was extended to include preventive care, curative, and rehabilitative services in the University of Hong Kong-Shenzhen Hospital in mainland China. ${ }^{2}$

\section{Challenges}

An interim review was conducted by the Food and Health Bureau of the Hong Kong SAR Government in 2011 during the EHCV's initial phase to examine its operation and the utilisation of vouchers. ${ }^{3}$ Their results indicated that although the elderly people had high awareness of the scheme, problems such as low utilisation rates of preventive services and chronic disease care were prevalent, and the scheme was unable to promote substantial behavioural changes. Similar challenges were reported by successive investigations..$^{4-7}$ A cross-sectional survey conducted in 2011 indicated that only $21 \%$ of the elderly people changed their health seeking behaviours from public to private healthcare using the vouchers. ${ }^{4}$ Although enhancements were made after review, another survey in 2015 revealed that several problems such as the low enrolment rate of private doctors persisted. ${ }^{6}$ In total, $32 \%$ of doctors and $37 \%$ of the elderly people reported feeling that the annual voucher amount (then HK\$2000) was insufficient based on a willing-to-pay study, which indicated that the voucher amount for private preventive services and chronic disease care was below the market price in Hong Kong. ${ }^{7}$

\section{Our interviews}

Recently, we conducted pilot interviews with five private primary care professionals to obtain their opinions on enhancements still needed to change the behaviours of the elderly people currently using the vouchers. These professionals with at least 10 years of work experience in the private sector were invited because of their familiarity with the private healthcare system. They had also enrolled in the EHCV Scheme and used the eHealth system. To facilitate in-depth discussions during the interview, and allow free expression of opinion, three openended questions were prepared based on the previously mentioned challenges. The interviews were conducted at the professionals' clinics outside of working hours between September and November 2017. Each interview lasted 20 to 30 minutes and the interviewer took written notes.

\section{Interview questions and selected responses}

1. What are the current barriers to using the eHealth system?

In general, all interviewees agreed that the eHealth system has greatly improved since 2009 and felt it was user-friendly:

- "The eHealth system now is user-friendly enough. I spent more than 4 minutes per case during the initiation of the system but I can just spend 1-2 minutes now."

- "The time spent in eHealth system for transactions is acceptable. I usually spend less than 5 minutes per case."

- "Although the transaction procedures are done by the nurses, I feel the time spent on the system is acceptable."

\section{What are your suggestions to officially promote the Scheme?}

The majority of the interviewees felt that the EHCV Scheme was sufficiently promoted by the government:

- "Although the promotion was not enough during start of the scheme, it has considerably improved recently."

- "Most of the elderly people knew of the scheme." 
- "We keep actively asking them to join the scheme."

- One of the interviewees suggested that very old people may not able to obtain information about the scheme: "Very old people, let us say older than 80 years, especially those living in elderly homes, are a minority population that do not have much information about the scheme as no relatives remind them to join it."

\section{Do you have any suggestions or new interventions to improve the voucher scheme?}

Some of the interviewees suggested the price is insufficient, while others commented on the price settings.

- "Clearly the price is not enough."

- "The amount should increase with age or by categories such as body check, dentistry..."

- "The price should increase for different needs such as chronic diseases."

- "The elderly people mostly spend their voucher amounts for chronic disease treatment and some of the drugs for their diseases are expensive."

Common ideas about monitoring the use of vouchers were pointed out.

- "A considerable voucher amount is spent on purchasing a new pair of glasses to comply with the optometrist's suggestion. Indeed, the need is not immediate and I doubt whether it is necessary."

- "Monitoring the use of vouchers or setting a maximum amount for particular services (eg, buying new glasses) is required."

Also, they suggested wider population coverage:

- "I suggest lowering the age eligibility to less than 65 years."

- "The scheme should be promoted among carers in elderly care homes so the elderly people knows how to use the vouchers."

\section{Suggestions to improve the Elderly Health Care Voucher scheme}

Empirical findings have shown that the relative price of public and private services is a significant determinant of people's healthcare choice..$^{8-11}$ Financial incentives, such as voucher programmes, could thus balance the demand of public and private services in a public-private mixed system. ${ }^{12,13}$ Some theoretical studies also indicated that subsidies on private services can effectively reduce the demand for free public services in some circumstances. ${ }^{14,15}$ For example, the adolescent voucher programme in Nicaragua improved access to contraceptives through health services. ${ }^{16}$

Some early challenges of Hong Kong's EHCV Scheme, such as the unfriendly eHealth system and poor elderly participation in the scheme, have been greatly improved; however, common problems still exist. Mainly, the annual voucher amount-HK\$2000 since 2014-remains insufficient despite a survey in 2015 suggesting that it should be increased to HK $\$ 4000 .^{6}$ This limited monetary amount prevents the elderly people, who have limited income to spend on healthcare services, from changing their behaviour and switching to using more private than public healthcare services. Moreover, preventive services and some drugs for chronic conditions are expensive in private clinics, which would result in the elderly people paying out of pocket for consultations. This reduces their willingness to visit private doctors, especially for diseases requiring multiple follow-ups; it can be expected that some elderly pepole would rather utilise their vouchers for common cold consultations. Therefore, increased voucher amounts and service group-oriented (eg, preventive services) vouchers are recommended. In addition, officials should enhance collaboration with service providers to encourage promotion of the EHCV Scheme, especially for preventive services. For example, patient education material developed by officials or professional groups is a useful means to deliver preventive care information to health service providers and patients in a busy clinic. ${ }^{17}$ This would improve coordination of preventive care for the elderly people, thus improving the self-care capability and quality of life of the elderly people, and reducing demand for hospitalisation. Finally, regular monitoring to ensure the quality of the EHCV Scheme is necessary to prevent improper use, such as clinics raising consultation fees after accepting vouchers or patients spending vouchers on unnecessary treatment or items such as new pairs of glasses.

Although comments from only five interviews were discussed in this commentary, the responses indicate that challenges remain. Further evaluations of different enhancement strategies for the costs and benefits of the EHCV Scheme are warranted.

\section{Author contributions}

All authors had full access to the data, contributed to the study, approved the final version for publication, and take responsibility for its accuracy and integrity.

$\mathrm{KC}$ Chong designed the study, interpreted the data, and drafted the commentary. H Fung and EK Yeoh assisted in data collection and revised the commentary.

\section{Acknowledgement}

We thank the physicians spending their time to provide their comments during the interviews.

\section{Conflicts of interest}

As the statistical adviser of the journal, KC Chong was not involved in the peer review process of this article. Other authors have disclosed no conflicts of interest. 


\section{Funding/support}

The work was supported by Health and Medical Research Fund (Project No.: 14152711). The funder had no role in study design, data collection, analysis, interpretation, or manuscript preparation.

\section{Ethics approval}

The study was approved by the Survey and Behavioural Ethics Committee of the Chinese University of Hong Kong. Verba consent was provided by all interviewees before conducting the interviews.

\section{References}

1. Health Care Voucher, Hong Kong SAR Government Background of Elderly Health Care Voucher Scheme. 2015. Available from: http://www.hcv.gov.hk/eng/pub_ background.htm. Accessed 8 Dec 2016.

2. Hong Kong SAR Government. Government to launch pilot scheme for use of Elderly Health Care Voucher at University of Hong Kong-Shenzhen Hospital (with photos). 2015. Available from: https://www.info.gov.hk/ gia/general/201510/05/P201510050880.htm. Accessed 8 Dec 2016.

3. Food and Health Bureau, Department of Health, Hong Kong SAR Government. Interim Review of Elderly Health Care Voucher Pilot Scheme. February 2011. Available from: http://www.hcv.gov.hk/files/pdf/ehcv_interim_ review report en.pdf. Accessed 8 Dec 2016.

4. Yam CH, Liu S, Huang OH, Yeoh EK, Griffiths SM. Can vouchers make a difference to the use of private primary care services by older people? Experience from the healthcare reform programme in Hong Kong. BMC Health Serv Res 2011;11:255.

5. Yam CH, Huang OH, Liu S, Griffiths SM. The impact of elderly healthcare voucher scheme on the primary care system-views of healthcare professionals in Hong Kong. Proceedings of the Annual Scientific Meeting by the Hong Kong College of Community Medicine. Hong Kong College of Community Medicine. 27 Nov 2011.

6. The Hong Kong Medical Association. Results of surveys on Elderly Health Care Voucher Scheme. April 2015. Available from: http://www.healthyhkec.org/SCE10/presentations/ seminar1/Dr.\%20Douglas\%20CHAN_Use\%20of\%20 HealthCare\%20Voucher.pdf. Accessed 8 Dec 2016.

7. Liu S, Yam CH, Huang OH, Griffiths SM. Willingness to pay for private primary care services in Hong Kong: are elderly ready to move from the public sector? Health Policy Plan 2013;28:717-29.

8. Martin S, Smith PC. Using panel methods to model waiting times for National Health Service surgery. J R Stat Soc Ser A Stat Soc 2003;166:369-87.

9. Propper $\mathrm{C}$. The demand for private health care in the UK. J Health Econ 2000;19:855-76.

10. Fabbri D, Monfardini C. Rationing the public provision of healthcare in the presence of private supplements: evidence from the Italian NHS. J Health Econ 2009;28:290304.

11. Hanson K, Yip WC, Hsiao W. The impact of quality on the demand for outpatient services in Cyprus. Health Econ 2004;13:1167-80.

12. King's Fund. Paying the patient: improving health using financial incentives. 2007. Available from: https://www. kingsfund.org.uk/sites/default/files/field/field_document/ paying-the-patient-kicking-bad-habits-supporting-paperkaren-jochelson.pdf. Accessed 8 Dec 2016.

13. Duckett SJ. Living in the parallel universe in Australia: public Medicare and private hospitals. CMAJ 2005;173:7457.

14. Chen W, Zhang ZG, Hua Z. Analysis of two-tier public service systems under a government subsidy policy. Computer Industrial Eng 2015;90:146-57.

15. Barros PP, Siciliani L. Public and Private Sector Interface. In: Pauly MV, McGuire TG, Barros PP. Handbook of Health Economics. North Holland: Elsevier; 2011: 927-1001.

16. Meuwissen LE, Gorter AC, Kester AD, Knottnerus JA. Does a competitive voucher program for adolescents improve the quality of reproductive health care? A simulated patient study in Nicaragua. BMC Public Health 2006;6:204.

17. Sin CK, Fu SN, Tsang CS, Tsui WW, Chan FH. Prevention in primary care is better than cure: The Hong Kong Reference Framework For Preventive Care for older adults-translating evidence into practice. Hong Kong Med J 2015;21:353-9.

\section{Answers to CME Programme Hong Kong Medical Journal October 2019 issue}

Hong Kong Med J 2019;25:349-55

\section{Emergency attendances and hospitalisations for complications after transrectal} ultrasound-guided prostate biopsies: a five-year retrospective multicentre study
A
1. False
2. False
3. True
4. True
5. True
B
1. True
2. False
3. False
4. False
5. True

Hong Kong Med J 2019;25:363-71

II. Epidemiology of respiratory syncytial virus infection and its effect on children with heart disease in Hong Kong: a multicentre review
A
1. False
2. True
3. False
4. False
5. True
1. True
2. False
3. False
4. True
5. False 